\title{
Comparative Morphological Investigation between Natural Photo-Aged of Two Different Low Density Polyethylene Green House Covers
}

\author{
BabaghayouMeriam Imane ${ }^{1}$, AbdelHamid Ismail Mourad ${ }^{* 2,3,4}$ \\ ${ }^{1}$ Ammar Telidji University, Laghouat, Algeria \\ ${ }^{2}$ Mechanical Engineering Department, United Arab Emirate University, Al Ain, UAE \\ ${ }^{3}$ National Water and Energy Center, United Arab Emirates University, Al Ain, UAE \\ ${ }^{4}$ On leave from Mechanical Design Department, Faculty of Engineering, Helwan University, Cairo,Egypt
}

Received: June 15, 2021; Accepted: July 20, 2021; Published: August 04, 2021

*Corresponding author: AbdelHamid Ismail Mourad, Mechanical Engineering Department, United Arab Emirate University, Al Ain, UAE E-mail: ahmourad@uaeu.ac.ae

\begin{abstract}
This work studies and compares the degradation performance of two different types of blown extruded films of low density polyethylene films used as greenhouse covers. The first one is LDPE (B24/2) supplied by ENIP Skikda and the other one is LDPE (2100 T N00W) supplied by SABIC, Saudi Arabia. Both films are commonly used in Algeria as greenhouse covers. The films were exposed outdoors over a period of 8 months for natural ageing. XRD and DSC analysis were conducted to characterize the thermal properties of the materials and compare between their degradation behaviors. The results revealed that the degradation resistance of LDPE (B24/2) is better than LDPE (2100T N00W) in term of their degree of crystallinity.
\end{abstract}

Keywords: Natural Ageing, LDPE (B24/2); LDPE (2100 T N00W); Degree of Crystallinity, XRD; DSC.

\section{Introduction}

Polyethylene (PE) is one of the mostly studied and exploited polymers due to its characteristics and wide range of applicability [1-5]. Depending on the density, polyethylene are classified as Linear low density (LLDPE), low density (LDPE), High density (HDPE) and ultra-high molecular weight (UHMWPE) [6-10]. Low density polyethylene films has a big demand on its use in agriculture field as greenhouse cover [11-15]. They have several appropriate characteristics (lightness transperancy), however its exposure to UV radiations leads to a dramatical loss in its properties (mechanical, chemical and morphological) due to the oxidation of its initial molecular structure [16-22]. The life time of the films is an essential factor. In this study the morphological aspect (crystallinity degree) during a natural ageing of a pair of films produced using two different raw materials (LDPE B24/4 a local product and LDPE $2100 \mathrm{~T}$ N00W an imported product) was the focal point. The techniques conducted to follow the evolution of the crystallinity degree for both materials were the Differential Scanning Calorimetric DSC ( thermal method) and the X-ray Diffraction analysis XRD (an optical method) [23-25].

\section{Experimental}

\section{Material and procedures}

The first raw material of LDPE used in this investigation is a commercial film produced by the ENIP Company, Skikda, Algeria under the reference "B24/2". The second raw material was a commercial grade produced in Saudi Arabia basic industries cooperation (SABIC) as pellets under the reference "LDPE 2100 T N00W". The polyethylene has been transformed to films from both materials under the same processing conditions in an Algerian industry SOFIPLAST. Both materials are a neat grade exempt of stabilizing agents.

Film cuts were mounted within wooden frames facing south, inclined at $45^{\circ}$, according to the standard NF T51-165. The solar exposure took place at Laghouat, Algeria $\left(38^{\circ}, 48 \mathrm{~N}\right)$ from March to November for both LDPE B24/2 and LDPE 2100T. The maximum time at which the films became too brittle to resist to the wind strength was found to be 8 months. Sampling process was done monthly.

\section{Characterization methods}

\section{Differential Scanning Calorimetry(DSC)}

DSC measurements were performed for the LDPE B24/2 on a DSC Mettler TA 3000 interfaced to a microcomputer controller 
and for LDPE 2100T on a NETZSCH DSC 204F1Phoenix. Indium was used for calibration and nitrogen as atmosphere for both. Samples of about 7-9 $\mathrm{mg}$ were heated from -150 to $200^{\circ} \mathrm{C}$ with a heating rate of $10^{\circ} \mathrm{C} / \mathrm{min}$ [26-30].

\section{$\mathrm{X}$ ray Diffractometry (XRD)}

X-raydiffractograms were obtained for both materials by means of an (XRD, PW3040 Philips Diffractometer, Cu K $\alpha$ radiation, $\lambda=0$, $154056 \AA$, voltage of $40 \mathrm{kV}$ and current of $50 \mathrm{~mA}$ ) over a range of $2 \theta=50-60^{\circ}$ with step of 0.04 and acquisition time of $3 \mathrm{~s}$.

\begin{tabular}{|c|c|c|c|c|c|c|c|c|}
\hline \multirow[b]{2}{*}{ Samples } & \multicolumn{2}{|c|}{$\mathrm{T}_{\mathrm{m}}\left({ }^{\circ} \mathrm{C}\right)$} & \multicolumn{2}{|c|}{$\Delta \mathrm{H}_{\mathrm{f}}(\mathrm{J} / \mathrm{g})$} & \multicolumn{2}{|c|}{$\mathrm{X} \%$ (DSC) } & \multicolumn{2}{|c|}{$\mathrm{X} \%$ (XRD) } \\
\hline & LDPE (B24/2) & $\begin{array}{c}\text { LDPE }(2100 \\
\text { T) }\end{array}$ & $\begin{array}{c}\text { LDPE } \\
\text { (B24/2) }\end{array}$ & $\begin{array}{c}\text { LDPE }(2100 \\
\mathrm{T})\end{array}$ & $\begin{array}{c}\text { LDPE } \\
\text { (B24/2) }\end{array}$ & $\begin{array}{c}\text { LDPE }(2100 \\
\mathrm{T})\end{array}$ & LDPE (B24/2) & $\begin{array}{c}\text { LDPE }(2100 \\
\text { T) }\end{array}$ \\
\hline A0 (0 month) & 107.5 & 111.1 & 100.9 & 139.29 & 35.40 & 47.54 & 36.01 & 47.1 \\
\hline A4 ( 4 months) & 108.7 & 111.4 & 104.9 & 150.08 & 36.81 & 51.19 & 37.43 & 51.33 \\
\hline A8 (8 months) & 108.87 & 112.4 & 110.2 & 191.52 & 38.67 & 65.36 & 41.67 & 59.08 \\
\hline
\end{tabular}

\section{Results and Discussion}

The DSC analysis has been conducted for the virgin material and for 4 and 8 months aged material. Figure 1 shows the peaks of fusion of both materials for the different exposure periods. It can be observed that peaks of fusion of LDPE $2100 \mathrm{~T}$ N00W films are larger and sharper than those of LDPE B24/2 which can be related to the rate of material crystallinity.

The area under the melting peak represents the heat of fusion which is proportional to the amount of crystals present in the sample. Its value is given directly by the DATA Analysis program of the apparatus. The mass-based degree of crystallinity noted $\mathrm{Xc}$, corresponds to the ratio of the heat of fusion of the current sample and that of a $100 \%$ crystalline polyethylene) $(\Delta \mathrm{Hfc}=285$ $\mathrm{j} / \mathrm{g}$ [ [31-32] by the relationship:

$$
\mathrm{x} \%=\quad \square \Delta \mathrm{H} \rrbracket_{-} \mathrm{f} /\left(\llbracket \Delta \mathrm{H} \rrbracket_{-} \mathrm{f}^{\wedge} \mathrm{c}\right)
$$

Based on the melting of the total volume of the sample the measurement is linked to the whole material under test which provides information with fidelity over the real crystallinity degree. In Table 1 the crystallinity degree is presented for three stages of ageing for both materials.

The melting temperature, heat of fusion and the degree of crystallinity of both films are given in Table 1 . It is noted that the degree of crystallinity increases with ageing exposure time and the melting temperature and heat of fusion follow the same trend. This trend of variation can be also seen in Figure 2. The Tm

for unaged film was found to have value of $107.5^{\circ} \mathrm{C}$ for LDPE B24/2 and $111.1^{\circ} \mathrm{C}$ for LDPE $2100 \mathrm{~T}$, respectively. The maximum increase in the $\mathrm{Tm}$ for both materials is about $1.37^{\circ} \mathrm{C}$ and $1.3 \mathrm{o} \mathrm{c}$. It can be concluded that the natural ageing time has no significant effect on the Tm of both films. The results show that LDPE 2100 $\mathrm{T}$ is more affected by ageing. Such observation can be linked to the structural changes undergone by the material duringexpo sure to solarradiation. UV radiation causes the breaking of molecular chains having the effect of increasing the crystallinity through a process of chemocrystallisation $[32,33]$. Indeed, these reactions confined tothe amorphous phaseleads toa decrease in the average molecular weight of the chains[33]. Short chain segmentsresultingtend to diffuseto the crystal lamellaethus increasing both the crystal concentrationand the value of the melting temperature.

To obtain another estimation of the crystallinity degree for both materials, the X-ray diffraction analysis was conducted on virgin and aged (for 4 and 8 months) films. The XRDat large anglesenables the calculation of the crystalline concentration. The diffraction profile was analyzed asa superposition of an amorphoushalo and crystallines pectrum. After deconvolution of the crystalline peaksand amorphoushalo, the crystallinity is determined according to the method of Hermans and Weidinger $[34,35]$ by calculating the total area Sccrystalline peaksdividedby the total area of all crystalline and amorphousdiffractingelement $\mathrm{sSc}+\mathrm{Sa}[34,36]$. The calculated degree of crystallinity X\% of both materials is presented in Table 1 . These results showan overall increase in the crystallinity (Figure 2) with ageing which confirms the results obtained by theDSC technique. The magnitude of the crystallinity degree is almost the samefor each material using the two techniques. It is note worthy that the crystallinity degree is higher for the SABIC film which explains the degrading rate is faster.

\section{Conclusion}

Based on the results of the DSC and XRD techniques, the ageing exposure time has adverse effect on both films. . The results of DSC and XRD regarding the degree of crystallinity are very close. The severe effect that the sunlight has on the $2100 \mathrm{~T}$ N00W film compared to that of B24/2 film is due to rapidity of the rate of chain scissions and in turns the high degree of crystallinity in this last one. This can be argued that the chemocristallisation phenomenon has taken place earlier in the LDPE (2100 T N00W) than in the LDPE (B24/2). The results of this work released that the LDPE B24/2 film has a relatively better thermal stability if compared to LDPE 2100 T N00W film. 


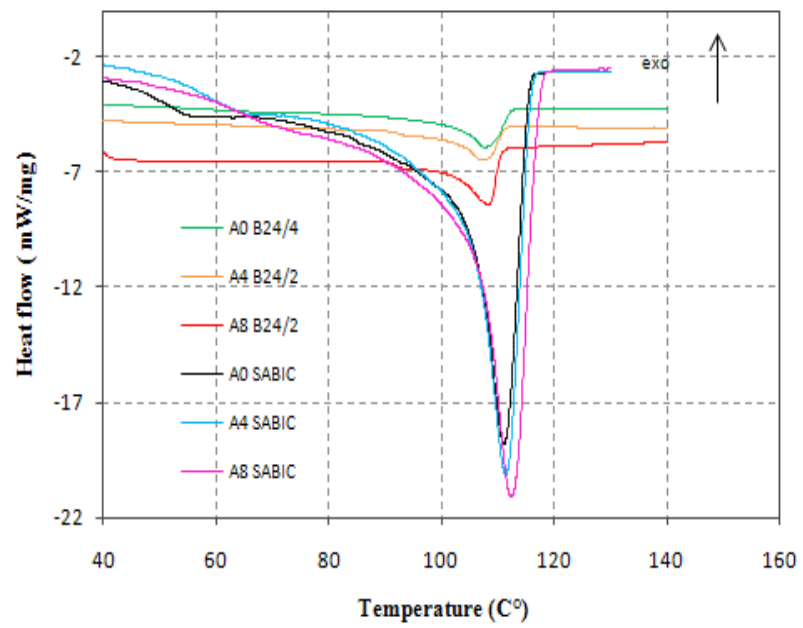

Figure 1: DSC curves of unstabilized LDPE ( B 24/2) and unstabilized LDPE (SABIC) (0 month, 4 and 8 months of ageing)

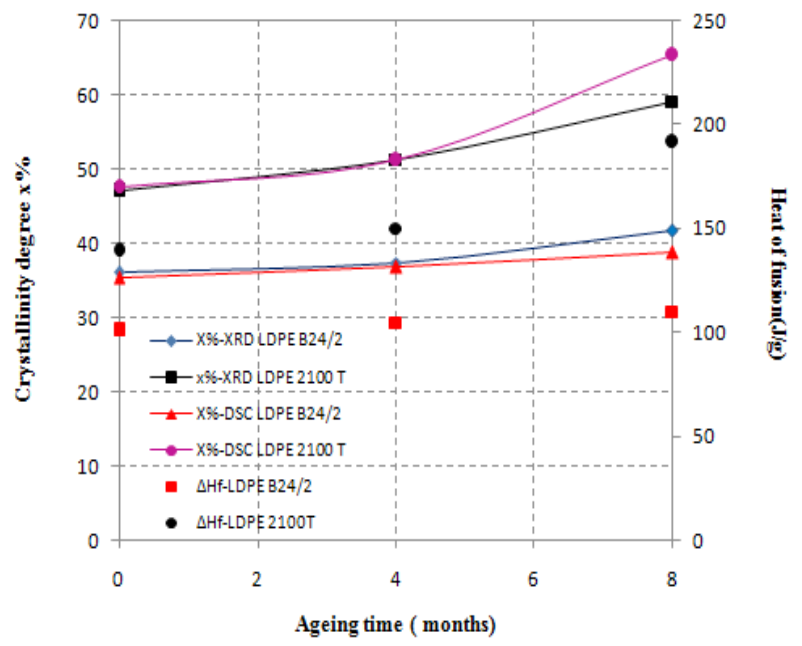

Figure 2: X\% (XRD and DSC) and enthalpy of melting vs. ageing time (solid lines for X\%).

\section{References}

1. Fouad H, Mourad AH, DC Barton. Effect of pre-heat treatment on the static and dynamic thermo-mechanical properties of ultra-high molecular weight polyethylene. Polymer Testing. 2005;24(5):549556.

2. Mourad AH, N Bekheet, Butch L. Latif D, Nafee, DC Barton. The effects of process parameters on the mechanical properties of die drawn polypropylene. Polymer Testing. 2005;24(2):169-180.

3. El Naas, Muftah H, Mourad, Hamid I, Riham Surkatti. Evaluation of the characteristics of polyvinyl alcohol (PVA) as matrices for the immobilization of Pseudomonas putida. International Biodeterioration \& Biodegradation. 2013;85:413-420.

4. Mourad, Rania, Soliman, Madkour. Characterisation of thermally treated and untreated polyethylene-polypropylene blends using DSC, TGA and IR techniques. Plastics, rubber and composites. 2009;38(7):265-278.
5. Mourad, Elsayed, Barton, Kenawy, Abdel. Ultra high molecular weight polyethylene deformation and fracture behaviour as a function of high strain rate and triaxial state of stress. International journal of fracture. 2003;120(3):501-515.

6. Mourad, Hamid I, Mozumder, Mairpady, Pervez, Kannuri. On the injection molding processing parameters of HDPE-TiO2 nanocomposites. Materials. 2017;10(1):85.

7. Benabid FZ, Kharchi, Zouai, Mourad, Hamid I, Benachour. Impact of comixing technique and surface modification of $\mathrm{ZnO}$ nanoparticles using stearic acid on their dispersion into HDPE to produce HDPE/ZnO nanocomposites. Polymers and Polymer Composites. 2019;27(7):389399.

8. Mozumder, Sayem, Mourad, Hamid I, Mairpady, Pervez, et al. Effect of $\mathrm{TiO}_{2}$ Nanofiller Concentration on the Mechanical, Thermal and Biological Properties of HDPE/TiO 2 Nanocomposites. Journal of 
Materials Engineering and Performance. 2018;27(5):2166-2181.

9. Mourad, Fouad, Elleithy. Impact of some environmental conditions on the tensile, creep-recovery, relaxation, melting and crystallinity behaviour of UHMWPE-GUR 410-medical grade. Materials \& Design. 2009;30(10):4112-4119.

10. Mohamed, Fouad H, Mourad, Barton. UV irradiation and aging effects on nanoscale mechanical properties of ultra high molecular weight polyethylene for biomedical implants. Plastics, rubber and composites. 2008;37(8):346-352.

11. Mourad, Abdelkader. On use of trilayer low density polyethylene greenhouse cover as substitute for monolayer cover. Plastics, Rubber and Composites. 2014;43(4):111-121.

12. Dehbi, Abdelkader, Mourad, Hamid I, Amar Bouaza. Ageing effect on the properties of tri-layer polyethylene film used as greenhouse roof. Procedia Engineering. 2011;10:466-471.

13. Mourad, Elsayed, Barton, Kenawy, Abdel. Ultra high molecular weight polyethylene deformation and fracture behaviour as a function of high strain rate and triaxial state of stress. International journal of fracture. 2003;120(3):501-515.

14. Dehbi A, Youssef, Chappey, Mourad, Picuno, Statuto. Multilayers polyethylene film for crop protection in harsh climatic conditions. Advances in materials science and engineering. 2017(2017).

15. Djakhdane K, Dehbi, Mourad, Zaoui, Picuno, P. The effect of sand wind, temperature and exposure time on tri-layer polyethylene film used as greenhouse roof. Plastics, Rubber and Composites. 2016;45(8):346351.

16. Mourad. Thermo-mechanical characteristics of thermally aged polyethylene/polypropylene blends. Mater Design. 2010;31:918.

17. Mourad, Akkad, Soliman, Madkour, Characterisation of thermally treated and untreated polyethylene-polypropylene blends using DSC, TGA and IR techniques. Macromol Eng. 2009;38:265.

18. Babaghayou, Mourad, Vicente L, Ulagares, Urreaga JM, Chabira SF, et al.Photodegradation characterization and heterogeneity evaluation of the exposed and unexposed faces of stabilized and unstabilized LDPE films. J Materials and Design. 2016;111:279-290.

19. Fouad MH; Mourad, Barton DC. UV irradiation and aging effects on nanoscale mechanical properties of ultra high molecular weight polyethylene for biomedical implants. Macromol Eng. 2008;37:346.

20. Fouad MH, Mourad, Barton, DC. Effect of pre-heat treatment on the static and dynamic thermo-mechanical properties of ultra-high molecular weight polyethylene. Polym Test. 2005;24:549.

21. Mourad AH, Bekheet N, Butch A, Latif L, Nafee D, Barton C. The effects of process parameters on the mechanical properties of die drawn polypropylene. Polym Test. 2005;24:169.

22. Hassini, Guenachi, Hamou, Saiter, Marais, Beucher. Polym Degrad Stab. 2002;75:247

23. Mejia E, Mourad, Faqer, Halwish, Hefeiti, Kashadi, et al. March. Impact on HDPE mechanical properties and morphology due to processing. In 2019 Advances in Science and Engineering Technology International Conferences (ASET). IEEE.

24. Mejia, Edgar B, Maqdi, Alkaabi, Alhammadi, Mazna et al. Upcycling of HDPE waste using additive manufacturing: feasibility and challenges. Advances in Science and Engineering Technology International Conferences (ASET). 2020:1-6.
25. Aouadi, Hellati, Guessoum, Mourad, Nizamudeen C. Impact of Samarium Acetylacetonate Catalyst on the Compatibilization of Poly (lactic acid)/Poly (ethylene-co-vinyl acetate) Blends: Thermomechanical, Chemical, and Viscoelastic Characterizations. Polymer Science. 2020;63(3):218-231.

26. Babaghayou, Imane, Mourad, Hamid I, Nizamudeen. Anisotropy evaluation of LDPE/LLDPE/PIB trilayer films. Advances in Science and Engineering Technology International Conferences (ASET). 2020:1-3.

27. Habib, Zeeshan, Abdoon, Mohammed, Ghebremedhin, Elkashlan, et al. Analysis of microbeads in cosmetic products in the United Arab Emirates. Environmental Pollution. 2020;258:113831.

28. Dehbi, Abdelkader, Mourad, Hamid I. Durability of mono-layer versus tri- layers LDPE films used as greenhouse cover: Comparative study. Arabian Journal of Chemistry. 2016;9:S282-S289.

29. Dehbi, Abdelkader, Djakhdane, Mourad, Hamid I. Impact of degradation of polyethylene films under simulated climatic conditions on their mechanical behaviour and thermal stability and lifetime. In Pressure Vessels and Piping Conference. 2012;55058:131-135.

30. B Wunderlich. Macromolecular Physics. Crystal Structure, Morphology, Defects; Academic Press: New York. 1973.

31.Abdelkader, Mourad, Abdel I, Djakhdane, Alnaqbi. Degradation of Thermomechanical Performance and Lifetime Estimation of Multilayer Greenhouse Polyethylene Films Under Simulated Climatic Conditions. Polymer engineering and science. 2014.

32. Yang R. Effects of inorganic fillers on the natural photo-oxidation of high-density Polyethylene. Polymer Degradation and Stability. 2005.

33. Guadagno L. Chemical and morphologial modifications of irradiated linear low density polyethylene (LLDPE). Polymer Degradation and Stability. 2001.

34. Babaghayou MI, Mourad, Chabira SF, Sebaa M. Anisotropy evolution of low density polyethylene greenhouse covering films during their service life, Polymer Testing. 2018;66:146-154.

35. Mourad, Abdel, Cherupurakal, Hafeez, Barsoum, Farah A, et al. Impact Strengthening of Laminated Kevlar/ ${ }_{\mathrm{E}}$ poxy Composites by Nanoparticle Reinforcement» Polymers. 2020;12:2814.

36. Iftikhar, Haris, Mourad, Ismail, Ahmad. An overview of friction stir welding of high-density polyethylene. In 2020 Advances in Science and Engineering Technology International Conferences (ASET). IEEE. 